\title{
Water-borne diclofenac affects kidney and gill integrity and selected immune parameters in brown trout (Salmo trutta f. fario)
}

\author{
Birgit Hoeger $^{\mathrm{a}}$, Bernd Köllner ${ }^{\mathrm{b}}$, Daniel R. Dietrich ${ }^{\mathrm{a}}$, Bettina Hitzfeld ${ }^{\mathrm{c}, *}$ \\ a Environmental Toxicology, University of Konstanz, Konstanz, Germany \\ ${ }^{\mathrm{b}}$ Friedrich-Loeffler Institute, Greifswald-Insel Riems, Germany \\ c Swiss Agency for the Environment, Forests and Landscape (SAEFL), Substances, \\ Soil and Biotechnology Division, 3003 Berne, Switzerland
}

\begin{abstract}
The detection of residues of various pharmaceuticals in surface waters during the last two decades has prompted concerns about possible adverse effects of this kind of pollution on aquatic organisms. The objective of the present study was to investigate effects of the non-steroidal anti-inflammatory drug diclofenac, one of the pharmaceuticals most prevalent in surface waters, on brown trout (Salmo trutta f. fario), a salmonid species native to German rivers. Brown trout were exposed to 0.5, 5 and $50 \mu \mathrm{g} / \mathrm{L}$ diclofenac for 7, 14 and 21 days, whereby the lowest exposure concentration is comparable with concentrations commonly found in the aquatic environment. Fish exposed to diclofenac displayed significantly reduced haematocrit levels after 7 and 14 days of exposure. After 21 days, trout were examined for histopathological alterations, whereby diclofenac exposure resulted in increased monocyte infiltration in the liver, telangiectasis in gills, and the occurrence of interstitial hyaline droplets, interstitial proteinaceous fluid and mild tubular necrosis in trunk kidney. Concurrent immunohistological analysis revealed an increase of granulocyte numbers in primary gill filaments, as well as granulocyte accumulation and increased major histocompatibility complex (MHC) II expression in kidney, suggestive of an inflammatory process in these organs. Moreover, the ability of diclofenac to hinder the stimulation of prostaglandin $\mathrm{E}_{2}$ synthesis was shown in head kidney macrophages of brown trout in vitro. These findings support the hypothesis that environmental exposure of fish to diclofenac provokes the same mechanism of action in these non-target organisms as previously described for mammalian species and can thus lead to similar (possibly adverse) effects. In general, the present study suggests that exposure of brown trout to diclofenac in concentration ranges commonly found in the environment can result in adverse effects in various organs and possibly compromise the health of affected fish populations.
\end{abstract}

Keywords: Pharmaceuticals; Diclofenac; Fish; Risk assessment

\section{Introduction}

* Corresponding author. Tel.: +41 3132317 68; fax: +413132479 78 .

E-mail address: bettina.hitzfeld@buwal.admin.ch (B. Hitzfeld).
With an annual usage of approximately $75 \mathrm{t}$ in Germany alone (Ternes, 1998), diclofenac is one 
of the most frequently applied non-steroidal antiinflammatory drug (NSAID). Due to its extensive use as analgesic and anti-rheumatic, diclofenac residues can nowadays be regularly detected in surface waters throughout the world. The potential of the current stateof-the-art sewage treatment plants (STP) to eliminate pharmaceutical residues, excreted by patients either as unmetabolised forms or metabolised molecules, which can subsequently be released and reactivated by bacterial activity, has previously been shown to be insufficient for a range of medical substances. For diclofenac, an elimination rate of about $69 \%$ occurs in STP (Ternes, 1998), with aerobic sludge age being an important determinant of biological degradation, probably due to diversification of the metabolic activity of microorganisms (Ternes et al., 2004). In German rivers, median diclofenac concentrations of $0.15 \mu \mathrm{g} / \mathrm{L}$ and peak concentration of $1.2 \mu \mathrm{g} / \mathrm{L}$ have been detected (Ternes, 1998). Diclofenac concentrations in effluent from STPs in Switzerland may range from 0.3 to $>0.9 \mu \mathrm{g} / \mathrm{L}$, while the concentration in rivers and lakes is in the range of $<1.0 \mathrm{ng} / \mathrm{L}-0.37 \mu \mathrm{g} / \mathrm{L}$ (Buser et al., 1998).

The mechanism of action of diclofenac in mammalian species is based on the inhibition of cyclooxygenases (COX) and subsequent inhibition of prostaglandin synthesis. Prostaglandins, however, not only play a role in mediating pain, but are involved in the regulation of blood circulation, vascular permeability and especially kidney function, including ion retention (Sali, 2005). Some of the adverse side effects associated with diclofenac therapy, such as nephropathy, are thought to be directly related to inhibition of prostaglandin synthesis (Sanchez et al., 2002). However, other effects, including formation of protein adducts and oxidative damage, have also been suggested as causative for adverse symptoms, e.g. gastrointestinal ulceration, nephropathy and idiosyncratic hepatotoxicity (Hargus et al., 1995).

In spite of the frequent findings of pharmaceutical residues in surface waters, there is still a paucity of ecotoxicological data, making a risk assessment for pharmaceuticals in aquatic organisms based on actual effect data in most cases impossible. Toxicity testing, based on acute endpoints, such as $\mathrm{EC}_{50}$ bacterial luminescence (30 min), algae growth (96h) or Daphnia magna mortality $(48 \mathrm{~h})$ suggests a rather low acute toxicity of diclofenac (Ferrari et al., 2003, 2004). However, the consequences of more subtle alterations in biochemical mechanisms due to chronic exposure to low concentrations are not known to date. First indications of adverse effects of diclofenac residues in fish, including pathogenic alterations in gills and kidney of rainbow trout after exposure to environmentally relevant diclofenac concentrations for 28 days have been described by Schwaiger et al. (2004).

The aim of the present study was to investigate effects of diclofenac exposure on organ pathology and selected immune parameters in a salmonid species native to German rivers. Therefore, brown trout (Salmo trutta f. fario) were exposed to nominal concentrations of $0.5,5$ and $50 \mu \mathrm{g} / \mathrm{L}$ diclofenac in a flow-through system for 7, 14 and 21 days. Subsequently, effects on general blood parameters, namely haematocrit and leucocrit values, as well as serum lysozyme activity were examined. Moreover, samples of liver, spleen, head and trunk kidney, gills and intestine were investigated for histopathological alterations and changes in prevalence and distribution of leucocyte populations and major histocompatibility complex (MHC) II with the help of fluorescence immunohistology. The ability of diclofenac to inhibit cyclooxygenase activity in fish macrophages was investigated, in order to demonstrate the same mode of action (prostaglandin synthetase suppression) in fish as was reported for mammalian species.

\section{Material and methods}

\subsection{Experimental set-up}

Brown trout (S. trutta f. fario) (aged $\sim 18$ months) were purchased from Peter Stoerk's hatchery (Bad Saulgau, Germany) and kept in $360 \mathrm{~L}$ aquaria, in groups of 36 fish per exposure concentration. After an acclimatisation period of 13 days, fish were exposed to water-borne diclofenac (2-[(2,6-dichlorophenyl) amino] benzene acetic acid sodium-potassium salt) (Sigma, Steinheim, Germany) at nominal concentrations of $0.5,5.0$ and $50 \mu \mathrm{g} / \mathrm{L}$, in a flow-through system for 21 days. Water from Lake Constance was used as a diluent and for control fish. Constant water flow through the aquaria was kept at $32 \mathrm{~L} / \mathrm{h}$, resulting in a replacement time of approximately $48 \mathrm{~h}$ for a complete exchange of water in the aquaria. In order to monitor diclofenac concentrations in the aquaria, 
daily water samples were frozen at $-20^{\circ} \mathrm{C}$ and later analysed with a diclofenac-specific ELISA.

\subsection{Diclofenac analysis of water samples with ELISA}

ELISA for diclofenac analysis followed the procedure reported by Deng et al. (2003). Diclofenac antibody and the coating antigen diclofenac-TG conjugate were kindly provided by Dr. Dietmar Knopp, Technical University Munich, Germany. All samples were tested in three independent ELISA runs.

\subsection{Fish sampling}

After 7, 14 and 21 days, 12 brown trout per treatment group were sampled. Fish were sacrificed and blood was taken from the caudal vein with a syringe, followed by determination of haematocrit/leucocrit values. Remaining blood was kept at $4{ }^{\circ} \mathrm{C}$ and later centrifuged at $1000 \mathrm{~g}$, for $15 \mathrm{~min}$, at $4{ }^{\circ} \mathrm{C}$ to obtain serum, which was stored at $-80^{\circ} \mathrm{C}$ until further analysis. At the 21 days time point, organ samples of six fish per treatment were taken for histological analysis. Gill samples and parts of intestine were washed in phosphate balanced salt solution (PBS) before fixation. Parts of head kidney, trunk kidney, spleen, liver and intestine as well as one gill arch were fixed in $4 \%$ paraformaldehyde (extra pure, Sigma-Aldrich, Seelze, Germany) in phosphate buffer according to Soerensen $(0.1 \mathrm{M}$ potassium dihydrogen phosphate and $0.1 \mathrm{M}$ di-sodium hydrogen phosphate, mixed at a ratio of $3 / 7$, resulting in a $\mathrm{pH}$ of 7.3) under constant shaking for at least $3 \mathrm{~h}$. Fixing solution was changed and samples kept at $4{ }^{\circ} \mathrm{C}$ overnight, followed by another exchange of the fixing solution. Samples were kept at $4{ }^{\circ} \mathrm{C}$ until paraffin embedding.

\subsection{Haematocrit and leucocrit values}

To determine haematocrit and leucocrit values, sodium heparin-treated micro haematocrit capillaries (VWR International, Bruchsal, Germany) were filled with fresh peripheral blood, closed with haematocrit sealing compound (Brand, Wertheim, Germany) and centrifuged at 12,000 rpm for $5 \mathrm{~min}$ in a Biofuge haemo with a special haematocrit rotor (Heraeus/Kendro Laboratory Products, Hanau, Germany). Haematocrit and leucocrit values were measured in percent filling of the capillary with the help of a haematocrit harp (Heraeus/Kendro Laboratory Products, Hanau, Germany).

\subsection{Serum lysozyme activity}

The method for measuring serum lysozyme follows the description of Ellis (1990) (turbimetric assay) and is based on the lysis of the Gram-positive bacterium Micrococcus lysodeikticus by serum lysozyme. The lysis of the bacterium can be detected in a spectrophotometer at $530 \mathrm{~nm}$ as a decrease in optical density (OD) of the M. lysodeikticus solution. $950 \mu \mathrm{L} \mathrm{M}$. lysodeikticus solution (Sigma, Steinheim, Germany) $(0.5 \mathrm{mg} / \mathrm{mL}$ in $0.05 \mathrm{M}$ sodium phosphate buffer $(\mathrm{pH}$ 6.2 ) were pipetted in a cuvette and measured, followed by the addition of $50 \mu \mathrm{L}$ of serum or plasma. Absorption was measured after $30 \mathrm{~s}, 1,2,3,4$ and $4.5 \mathrm{~min}$ and lysozyme activity was expressed as decrease of optical density per minute.

\subsection{Histology}

Formalin-fixed tissue samples were embedded in paraffin using standard procedures. Serial sections of $4 \mu \mathrm{m}$ were cut and mounted on slides, dried overnight at $50^{\circ} \mathrm{C}$ and stored at room temperature for subsequent investigation. Paraffin sections were deparaffinised and re-hydrated with the following procedure: $2 \times 5 \mathrm{~min}$ in RotiHistol (Carl Roth GmbH, Karlsruhe, Germany), $2 \times 3$ min in $100 \% n$-propanol, 3 min each in 96, 80, 70 and 50\% n-propanol, followed by short incubation in MQ-water. One set of slides was stained with haematoxylin/eosin following standard procedures and examined for histopathological alterations on a Zeiss Axiolab microscope (Carl Zeiss, Hallbergmoos, Germany).

\subsection{Immunohistology}

Demasking of deparaffinised and re-hydrated sections was conducted in a 1:1.7 mixture of $0.01 \mathrm{M}$ citrate buffer and $0.2 \mathrm{M}$ sodium-dihydro-phosphate $\left(\mathrm{NaH}_{2} \mathrm{PO}_{4}\right)$ buffer for $20 \mathrm{~min}$ at $120^{\circ} \mathrm{C}$. After cooling down to room temperature, sections were washed twice in PBS and incubated with Starting Block ${ }^{\mathrm{TM}}$ (TBS) blocking buffer (Pierce, Rockford, USA) for $30 \mathrm{~min}$ at room temperature (RT). After $3 \times$ washing 
Table 1

List of primary antibodies used for immunohistology

\begin{tabular}{ll}
\hline Cell type or surface marker & Primary antibody \\
\hline Granulocytes & Monocloncal antibody (mab) Q4E \\
& (Kuroda et al., 2000) \\
Thrombocytes & Mab 22 (Köllner et al., 2004) \\
MHC II & Mab IE7 (Stachowski et al., 2004) \\
\hline
\end{tabular}

in PBS, sections were incubated with the respective primary antibody (see Table 1) diluted in Iscove's Modified Dulbecco's medium (Invitrogen, Karlsruhe, Germany) for $1 \mathrm{~h}$ at RT, followed by another wash cycle and subsequent incubation with secondary antibody (Goat-anti-mouse IgG/IgM-Alexa Fluor 488, MoBiTec, Goettingen, Germany) for $1 \mathrm{~h}$ at RT. After washing, sections were mounted in PBS containing $10 \%$ glycerin and 2.5\% 1,4-diazobicyclooctan (Dabco) (Sigma, Steinheim, Germany), enclosed with cover slips and examined for specific fluorescence with a LSM 510 confocal laser scanning microscope (Carl Zeiss, Hallbergmoos, Germany). The sections were scanned in confocal mode using a $40 \times$ oil immersion objective. The $488 \mathrm{~nm}$ line of an argon laser was used for Alexa 488 excitation. The fluorescence emission was recorded at $525 \mathrm{~nm}$ using a main beam splitter at $488 / 543 \mathrm{~nm}$ in combination with a second beam splitter at $545 \mathrm{~nm}$ and an emission filter from 503 to $530 \mathrm{~nm}$. The confocal laser scanning microscope was set-up using conjugate control sections leaving no background of unspecific fluorescence or improper optical or electronic signal amplification. Labelled sections were then scanned under the same scanning conditions for all parameters applied for the conjugate control samples. The obtained scans were analysed using the LSM 510/2.1 software package (Carl Zeiss, Hallbergmoos, Germany). Four section areas of gills, spleen, liver, head and trunk kidney and lower intestine of at least four brown trout were analysed per treatment. The pictures were compared and those showing typical staining (fluorescence intensity and distribution of stained cells) were used to compare treatment effects. Furthermore, samples showing strong differences to the 'type picture' were also selected to describe the overall range of induced alterations. Differences in the green/red intensity of tissue autofluorescence between different samples, as can been seen in the pictures, are due to day-to-day variations in the set-up of the fluorescence scanner, which was adjusted using the respective daily negative control.

\subsection{In vitro cyclooxygenase inhibition in head kidney macrophages}

Head kidney macrophages were isolated following the procedure described by Secombes (1990). The protocol for the cyclooxygenase inhibition studies was adapted for brown trout macrophages following the description by Zou et al. (1999). Briefly, macrophages were seeded at a density of $1 \times 10^{6}$ cells $/ 500 \mu \mathrm{L}$ in 24 well tissue culture plates (Greiner, Frickenhausen, Germany) and left for several hours to allow attachment to the plate, followed by stimulation with $5 \mathrm{mg} / \mathrm{mL}$ lipopolysaccharide (LPS from Escherichia coli serotype 0111:B4; Sigma, Steinheim, Germany) for $12 \mathrm{~h}$. Cells were then pre-incubated with $10 \mathrm{nM}-10 \mu \mathrm{M}$ diclofenac for $30 \mathrm{~min}$, followed by stimulation with calcium ionophore A23187 (Sigma, Steinheim, Germany) for $20 \mathrm{~min}$. Cell supernatants were kept at $-80^{\circ} \mathrm{C}$ pending prostaglandin $\mathrm{E}_{2}\left(\mathrm{PGE}_{2}\right)$ analysis with the help of a $\mathrm{PGE}_{2}$ biotrak assay (Amersham Biosiences, Little Chalfont Buckinghamshire, UK), according to the manufacturers instructions.

\subsection{Statistics}

Statistical analysis of data was performed using SAS JMP Version 4.0.4 (SAS Institute Inc., Heidelberg, Germany) and GraphPad Prism 3.0 (GraphPad Software Inc., San Diego, USA). In case of homogeneity of variances and normal distribution of data, differences between treatment groups were determined with one-way ANOVA with Dunnett's post test against the reference group exposed to Lake Constance water. Semi-quantitative data from histopathology was analysed with Kruskal-Wallis non-parametric ANOVA and Dunn's multiple comparison test as post test.

\section{Results}

\subsection{ELISA analysis of diclofenac concentrations in aquaria}

ELISA analysis of daily water samples demonstrated that the actual mean diclofenac concentrations 
( \pm standard deviation) in the exposure aquaria were $1.15 \pm 0.37,6.63 \pm 1.08$ and $63.05 \pm 5.61 \mu \mathrm{g} / \mathrm{L}$ for the nominal concentrations of $0.5,5$ and $50 \mu \mathrm{g} / \mathrm{L}$, respectively. The diclofenac concentrations in water samples from the reference aquarium (water from the Lake Constance) were below the limit of detection of $20 \mathrm{ng} / \mathrm{L}$, stated by Deng et al. (2003).

\subsection{Haematocrit and leucocrit values}

Packed erythrocyte volume in percent of total blood volume was significantly reduced in brown trout after exposure to nominal concentrations of 0.5 and $50 \mu \mathrm{g}$ diclofenac/L for 7 days and after exposure to $0.5,5$ and $50 \mu \mathrm{g} / \mathrm{L}$ group for 14 days, without displaying a concentration-effect relationship (Fig. 1a). After exposure to diclofenac for 21 days, diclofenac-exposed fish did not display lower haematocrit values than control
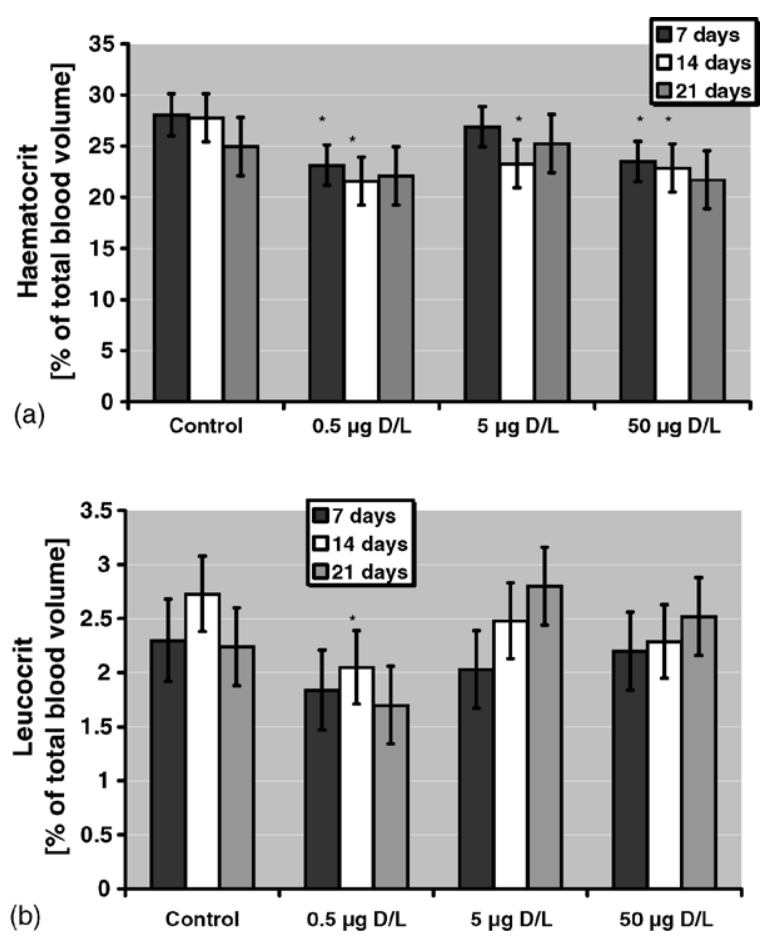

Fig. 1. Mean haematocrit (a) and leucocrit (b) values (given as percent of blood volume) from brown trout (S. trutta f. fario) exposed to nominal diclofenac (D) concentrations of $0.5,5$ and $50 \mu \mathrm{g} / \mathrm{L}$ for 7,14 and 21 days. Data was tested using one-way ANOVA with Dunnett's post test. Error bars indicate $95 \%$ confidence intervals (CI); $N \geq 11$; ${ }^{*} p \leq 0.05$. fish. However, at this time point, haematocrit values in control trout were also lower than in control fish at the earlier time points. This difference between control groups at different time points was, however, not statistically significant. Diclofenac did not cause a significant change in leucocrit values in exposed fish, except that leucocrit values were significantly lower in brown trout exposed to $0.5 \mathrm{pg} / \mathrm{L}$ for 14 days compared to controls (Fig. 1b).

\subsection{Serum lysozyme activity}

Diclofenac exposure did not result in a clear-cut effect on serum lysozyme activity in brown trout. Although exposure to $0.5 \mu \mathrm{g} / \mathrm{L}$ diclofenac for 7 days resulted in significantly lower lysozyme activity, and exposure to $5 \mu \mathrm{g} / \mathrm{L}$ for 21 days significantly increased lysozyme activity (Fig. 2), these differences are not considered to bear any biological significance due to the lack of a dose- and dose-time-response.

\subsection{Histopathological alterations in trunk kidney, gills and liver of brown trout}

Exposure to diclofenac over 21 days resulted in mild to moderate breakdown of pillar cells of secondary gill lamellae (telangiectasis) in all diclofenac exposure groups (Table 2). Exposure to $50 \mu \mathrm{g} / \mathrm{L}$ diclofenac, moreover, led to a significantly increased incidence of secondary lamellar clubbing. Furthermore, epithelial

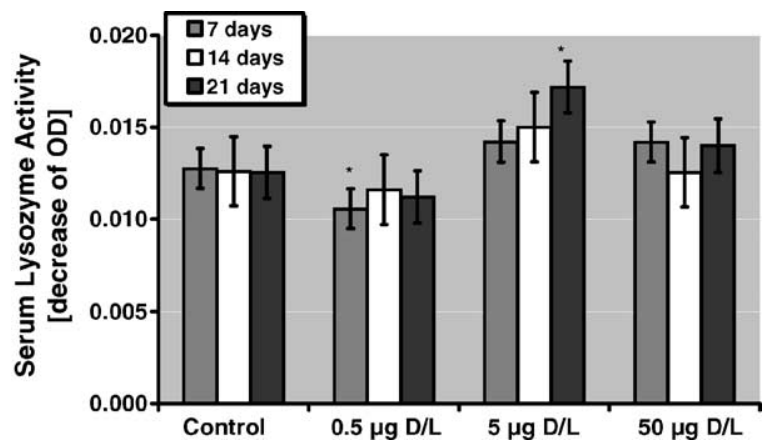

Fig. 2. Mean values for serum lysozyme activity (measured as decrease of optical density (OD) of a M. lysodeikticus solution) from brown trout (S. trutta f. fario) exposed to nominal diclofenac (D) concentrations of $0.5,5$ and $50 \mu \mathrm{g} / \mathrm{L}$ for 7,14 and 21 days. Data was tested using one-way ANOVA with Dunnett's post test. Error bars indicate $95 \% \mathrm{CI} ; N \geq 11 ;{ }^{*} p \leq 0.05$. 
Table 2

Histopathological effects of diclofenac on gills after exposure for 21 days

\begin{tabular}{|c|c|c|c|c|c|c|}
\hline Diclofenac $(\mu \mathrm{g} / \mathrm{L})$ & Telangiectasis & Hyperplasia & Thickened tips & $\begin{array}{l}\text { Muceous cell } \\
\text { hyperplasia }\end{array}$ & $\begin{array}{l}\text { Secondary } \\
\text { lamellar fusion }\end{array}$ & $\begin{array}{l}\text { Lamellar } \\
\text { clubbing }\end{array}$ \\
\hline Control & $0(6 / 6)$ & $0(6 / 6)$ & $0(6 / 6)$ & $0(6 / 6)$ & $0(6 / 6)$ & $0(6 / 6)$ \\
\hline & $0(1 / 6)$ & $0(5 / 6)$ & & & & \\
\hline 0.5 & $\begin{array}{l}1(2 / 6) \\
2(1 / 6) \\
3(2 / 6)\end{array}$ & $1(1 / 6)$ & $0(6 / 6)$ & $0(6 / 6)$ & $0(6 / 6)$ & $0(6 / 6)$ \\
\hline 5 & $\begin{array}{l}0(2 / 4) \\
3(2 / 4)\end{array}$ & $\begin{array}{l}0(2 / 4) \\
1(2 / 4)\end{array}$ & $1(1 / 4)$ & $\begin{array}{l}0(5 / 6) \\
1(1 / 6)\end{array}$ & $2(1 / 4)$ & $0(4 / 4)$ \\
\hline & $0(2 / 6)$ & $0(4 / 6)$ & & & $0(4 / 6)$ & $0(2 / 6)^{* *}$ \\
\hline 50 & $\begin{array}{l}2(3 / 6) \\
3(1 / 6)\end{array}$ & $1(2 / 6)$ & $0(6 / 6)$ & $0(6 / 6)$ & $\begin{array}{l}1(1 / 6) \\
2(1 / 6)\end{array}$ & $\begin{array}{l}1(3 / 6)^{* *} \\
2(1 / 6)^{* *}\end{array}$ \\
\hline
\end{tabular}

Rating of histopathological effects: $0=$ normal; $1=$ mild; $2=$ mild to moderate; $3=$ moderate; $4=$ severe. In brackets: number of trout, which showed the described effect/number of trout histopathologically analysed. Data was tested with Kruskal-Wallis non-parametric ANOVA.

*** $p \leq 0.01$.

cell hyperplasia, thickened lamellar tips and secondary lamellar fusion were occasionally observed. The most common histopathological effect in trunk kidney was the occurrence of interstitial hyaline droplets (mild) in all groups exposed to diclofenac (Table 3). Interstitial proteinaceous fluid (mild to moderate) and mild tubular necrosis was also frequently observed after exposure to the higher diclofenac concentrations for 21 days. In addition, diclofenac-exposed fish presented with proteinaceous casts (precipitated protein and cell debris within the tubule) as well as intratubular and intravascular proteinaceous fluid. Histopathological alterations in the liver of diclofenac-exposed brown trout included monocyte infiltration/accumulation, which was most notable in fish exposed to $5 \mu \mathrm{g} / \mathrm{L}$ diclofenac, as well as sinusoid distension, diffuse cytoplasm and focal necrosis (Table 4). Moreover, single incidences of interstitial proteinaceous fluid, foci of enhanced basophilia and scanty cytoplasm were observed.

\subsection{Immunohistological detection of different leucocyte populations}

Immunohistological detection of leucocyte populations in trunk kidney sections revealed a remarkable increase of granulocytes in interstitial tissue along

Table 3

Effects of diclofenac on trunk kidney after exposure for 21 days

\begin{tabular}{lllllll}
\hline $\begin{array}{l}\text { Diclofenac } \\
(\mu \mathrm{g} / \mathrm{L})\end{array}$ & $\begin{array}{l}\text { Interstitial hyaline } \\
\text { droplets }\end{array}$ & $\begin{array}{l}\text { Interstitial } \\
\text { proteinaceous fluid }\end{array}$ & $\begin{array}{l}\text { Tubular } \\
\text { necrosis }\end{array}$ & $\begin{array}{l}\text { Proteinaceous } \\
\text { casts }\end{array}$ & $\begin{array}{l}\text { Intratubular } \\
\text { proteinaceous fluid }\end{array}$ & $\begin{array}{l}\text { Intravascular } \\
\text { proteinaceous fluid }\end{array}$ \\
\hline Control & $0(6 / 6)$ & $0(6 / 6)$ & $0(6 / 6)$ & $0(6 / 6)$ & $0(6 / 6)$ & $0(6 / 6)$ \\
0.5 & $0(1 / 6)$ & $0(6 / 6)$ & $0(6 / 6)$ & $0(6 / 6)$ & $0(6 / 6)$ & $0(6 / 6)$ \\
& $1(5 / 6)$ & & & & $0(6 / 6)$ \\
5 & $0(4 / 6)$ & $0(3 / 6)$ & $0(6 / 6)$ & $0(6 / 6)$ & $0(5 / 6)$ & $1(1 / 6)$ \\
& $1(2 / 6)$ & $1(3 / 6)$ & & & \\
50 & $0(3 / 6)$ & $0(1 / 6)^{* *}$ & $0(3 / 6)^{*}$ & & $0(5 / 6)$ \\
& $1(1 / 6)$ & $1(2 / 6)^{* *}$ & $1(1 / 6)^{*}$ & $0(5 / 6)$ & $1(1 / 6)$ & $1(1 / 6)$ \\
& $2(2 / 6)$ & $2(2 / 6)^{* *}$ & $2(2 / 6)^{*}$ & $1(1 / 6)$ & & \\
\hline
\end{tabular}

Rating of histopathological effects: $0=$ normal; $1=$ mild; $2=$ mild to moderate; $3=$ moderate; $4=$ severe. In brackets: number of trout, which showed the described effect/number of trout histopathologically analysed. Data was tested with Kruskal-Wallis non-parametric ANOVA.

${ }^{*} p \leq 0.05$.

*** $p \leq 0.01$. 
Table 4

Effects of diclofenac on liver after exposure for 21 days

\begin{tabular}{|c|c|c|c|c|c|c|c|}
\hline $\begin{array}{l}\text { Diclofenac } \\
(\mu \mathrm{g} / \mathrm{L})\end{array}$ & $\begin{array}{l}\text { Monocyte } \\
\text { infiltration/accumulation }\end{array}$ & $\begin{array}{l}\text { Sinusoid } \\
\text { distension }\end{array}$ & $\begin{array}{l}\text { Diffuse } \\
\text { cytoplasm }\end{array}$ & $\begin{array}{l}\text { Focal } \\
\text { necrosis }\end{array}$ & $\begin{array}{l}\text { Foci of enhanced } \\
\text { basophilia }\end{array}$ & $\begin{array}{l}\text { Interstitial } \\
\text { proteinaceous fluid }\end{array}$ & $\begin{array}{l}\text { Scanty } \\
\text { cytoplasm }\end{array}$ \\
\hline Control & $0(6 / 6)$ & $0(6 / 6)$ & $0(6 / 6)$ & $0(6 / 6)$ & $0(6 / 6)$ & $0(6 / 6)$ & $0(6 / 6)$ \\
\hline 0.5 & $\begin{array}{l}0(4 / 6) \\
1(2 / 6)\end{array}$ & $\begin{array}{l}0(5 / 6) \\
2(1 / 6)\end{array}$ & $0(6 / 6)$ & $0(6 / 6)$ & $0(6 / 6)$ & $0(6 / 6)$ & $\begin{array}{l}0(4 / 6) \\
1(2 / 6)\end{array}$ \\
\hline 5 & $\begin{array}{l}0(1 / 6)^{* *} \\
1(2 / 6)^{* *} \\
2(3 / 6)^{* *}\end{array}$ & $\begin{array}{l}0(4 / 6) \\
1(2 / 6)\end{array}$ & $\begin{array}{l}0(4 / 6) \\
1(1 / 6) \\
2(1 / 6)\end{array}$ & $\begin{array}{l}0(4 / 6) \\
1(1 / 6) \\
2(1 / 6)\end{array}$ & $\begin{array}{l}0(5 / 6) \\
1(1 / 6)\end{array}$ & $\begin{array}{l}0(5 / 6) \\
1(1 / 6)\end{array}$ & $\begin{array}{l}0(5 / 6) \\
1(1 / 6)\end{array}$ \\
\hline 50 & $\begin{array}{l}0(2 / 6) \\
1(3 / 6) \\
2(1 / 6)\end{array}$ & $\begin{array}{l}0(3 / 6) \\
1(2 / 6) \\
2(1 / 6)\end{array}$ & $\begin{array}{l}0(5 / 6) \\
2(1 / 6)\end{array}$ & $\begin{array}{l}0(3 / 6) \\
1(3 / 6)\end{array}$ & $\begin{array}{l}0(5 / 6) \\
1(1 / 6)\end{array}$ & $\begin{array}{l}0(5 / 6) \\
1(1 / 6)\end{array}$ & $0(6 / 6)$ \\
\hline
\end{tabular}

Rating of histopathological effects: $0=$ normal; $1=$ mild; $2=$ mild to moderate; $3=$ moderate; $4=$ severe. In brackets: number of trout, which showed the described effect/number of trout histopathologically analysed. Data was tested with Kruskal-Wallis non-parametric ANOVA.

** $p \leq 0.01$.

with an increase in MHC II expression likely resembling an inflammatory process in diclofenac-exposed fish (Fig. 3). Moreover, in fish exposed to the lower diclofenac concentrations, the increase of MHC II coincided with a loss of morphological integrity of MHC II expressing cells. However, this reaction did not follow a dose-dependent pattern. While the nominal concentrations of 0.5 and $5 \mu \mathrm{g} / \mathrm{L}$ increased MHC II expression, exposure to $50 \mu \mathrm{g} / \mathrm{L}$ diclofenac resulted in depressed MHC II expression. Distribution and prevalence of thrombocytes were not altered in kidney samples of diclofenac-exposed trout compared to control fish.

In the primary gill lamellae of trout exposed to $0.5 \mu \mathrm{g} / \mathrm{L}$ diclofenac, a high prevalence of granulocytes was observed compared to control fish (Fig. 4). Thrombocyte numbers and distribution in tissue as well as MHC II expression were not affected in gill samples of diclofenac-exposed fish compared to control fish.

In all other tissues investigated, including head kidney, spleen, liver and intestine, diclofenac exposure did not result in any clearly visible alterations in prevalence and distribution of thrombocytes, granulocytes and MHC II expression compared to control fish.

\subsection{In vitro cyclooxygenase inhibition in head kidney macrophages}

Stimulation of head kidney macrophages with lipopolysaccharide and the calcium ionophore A23187 resulted in a clear induction of prostaglandin $\mathrm{E}_{2}$ synthesis. $\mathrm{PGE}_{2}$ induction was significantly inhibited by
$100 \mathrm{nM}(31.8 \mathrm{ng} / \mathrm{L})$ diclofenac (Fig. 5). PGE 2 synthesis further decreased at diclofenac concentrations of $500 \mathrm{nM}$ and $1 \mu \mathrm{M}$. However, with the concentrations applied, no real dose-response curve was found. At a concentration of $10 \mu \mathrm{M}$, diclofenac $\mathrm{PGE}_{2}$ synthesis was back to levels found in untreated and vehicle control cells and cells exposed to $10 \mu \mathrm{M}$ diclofenac only.

\section{Discussion}

The aim of the present study was to investigate possible effects of environmentally relevant diclofenac concentrations on a native salmonid species. In German rivers, median diclofenac concentrations of $0.15 \mu \mathrm{g} / \mathrm{L}$ and peak concentrations of $1.2 \mu \mathrm{g} / \mathrm{L}$ have been detected (Ternes, 1998). In the study at hand, ELISA analysis of water samples from the exposure aquaria demonstrated actual mean diclofenac concentrations of 1.15 , 6.63 and $63.05 \mu \mathrm{g} / \mathrm{L}$ for the nominal concentrations of $0.5,5$ and $50 \mu \mathrm{g} / \mathrm{L}$, respectively. Effects of diclofenac exposure on erythrocyte numbers in peripheral blood and on histological parameters were already observed at the lowest concentration, which is in the range of diclofenac concentrations found in surface waters, thus, emphasising the relevance of the study at hand. In order to cover a wide range of possible target tissues and modes of action, haematocrit and leucocrit values, serum lysozyme activity as well as histopathological changes and the abundance and distribution of different white blood cell populations in organs were examined. 

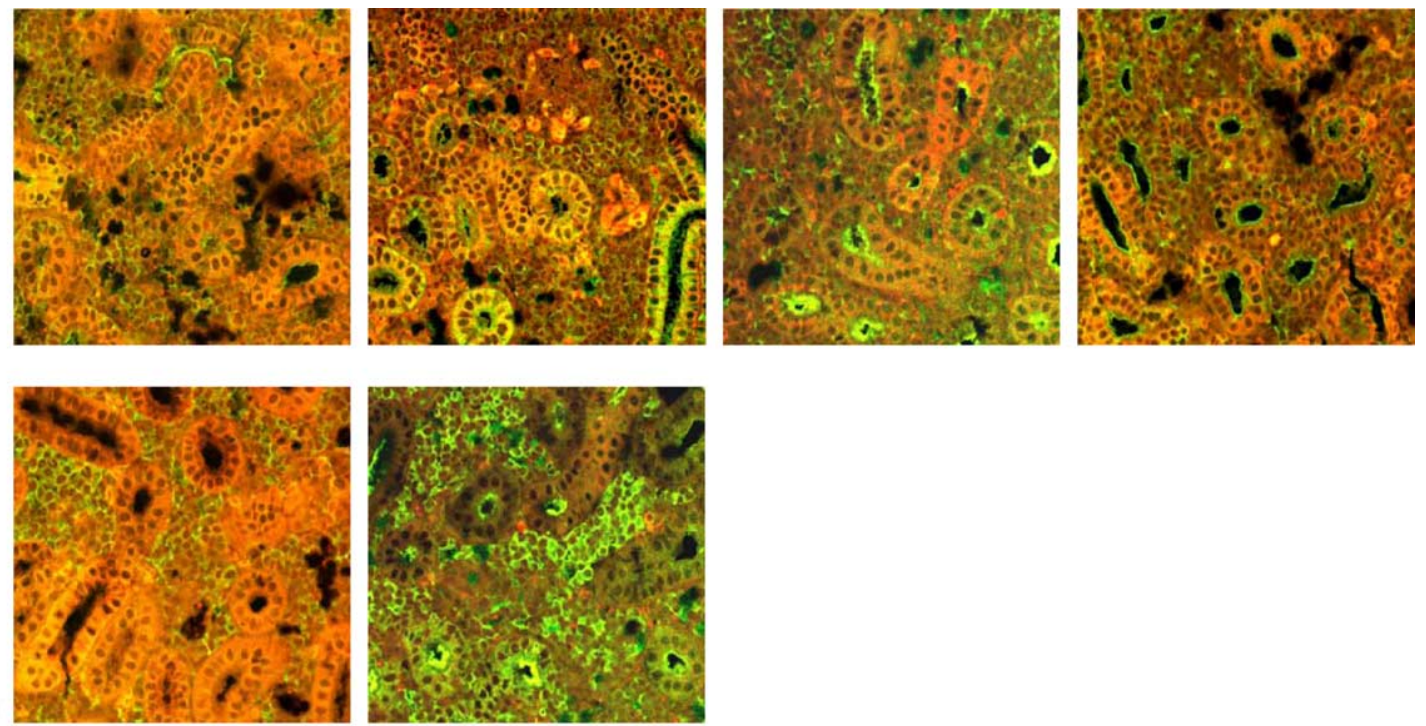

\section{Control}
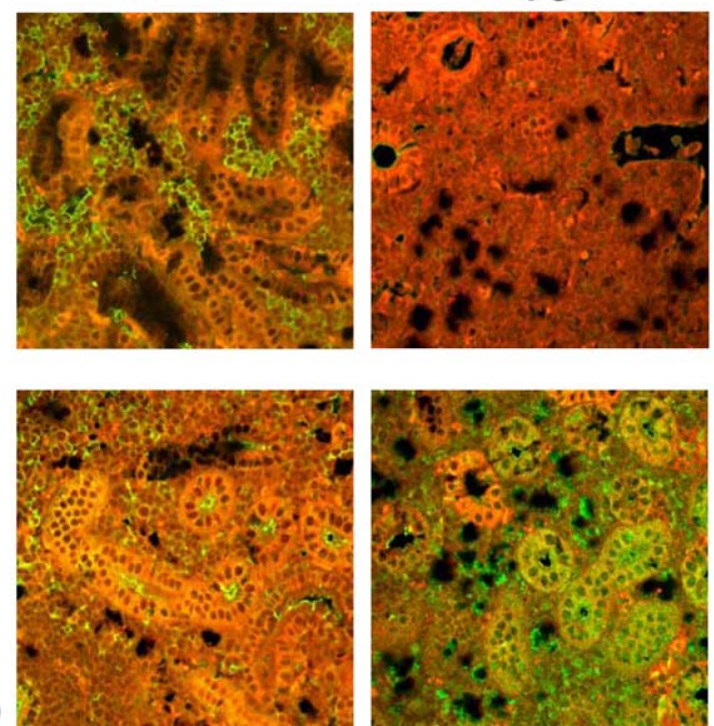

$5 \mu \mathrm{g} / \mathrm{L}$
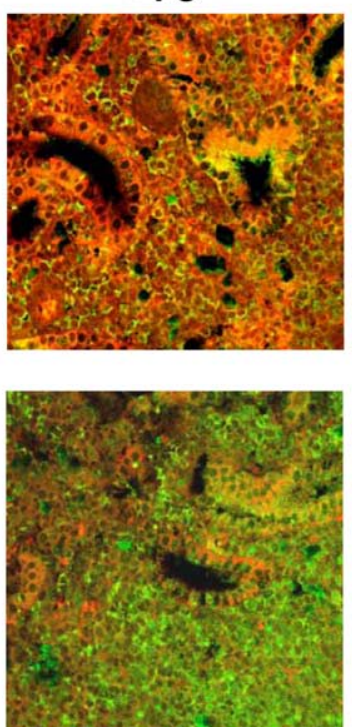

(b)

Fig. 3. Immunohistological detection of granulocytes (a) and major histocompatibility complex (MHC) II (b) in trunk kidney samples of diclofenac-exposed fish. In the first row of (a) and (b), the pictures representing the average of the reaction observed in the examined trout are shown. However, two of the four trout investigated showed a severe accumulation of granulocytes in kidney after exposure to $0.5 \mu \mathrm{g} / \mathrm{L}$ diclofenac (a) (second row). Exposure to 0.5 and $5 \mu \mathrm{g} / \mathrm{L}$ diclofenac, moreover, led to a loss of morphological integrity of kidney tissue in two out of four fish per exposure concentration, along with a strong increase in MHC II expression in one of these two fish per concentration, while MHC II expression was decreased in all five fish investigated after exposure to $50 \mu \mathrm{g} / \mathrm{L}$. Differences in the green/red intensity of tissue autofluorescence between different samples, as can been seen in the pictures, are due to day-to-day variations in the set-up of the fluorescence scanner, which was adjusted using the respective daily negative control. 


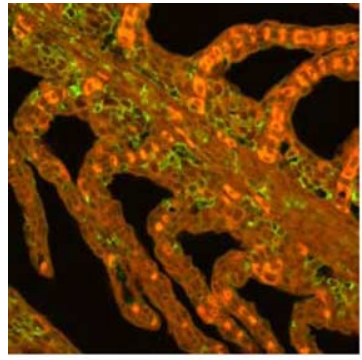

Control

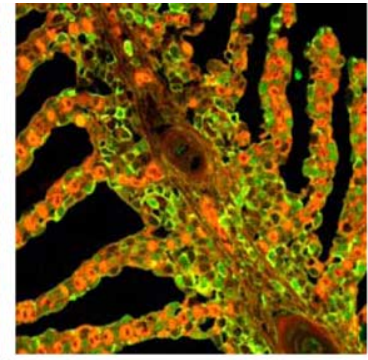

$0.5 \mu \mathrm{g} / \mathrm{L}$

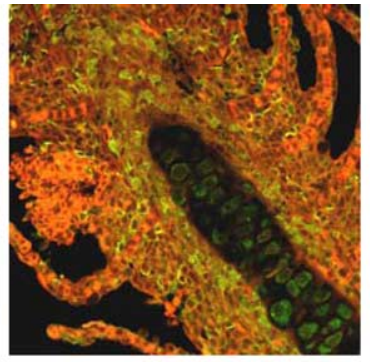

$5 \mu \mathrm{g} / \mathrm{L}$

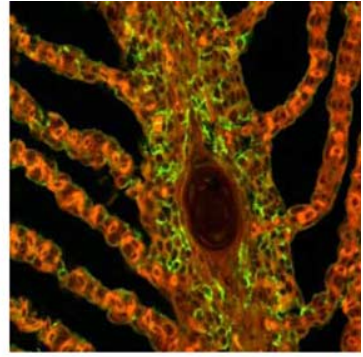

$50 \mu \mathrm{g} / \mathrm{L}$

Fig. 4. Immunohistological detection of granulocytes in gill samples of diclofenac-exposed brown trout (S. trutta f. fario). Exposure to diclofenac led to a clear increase in granulocytes in primary lamellae, which was most prominent in the trout exposed to $0.5 \mu \mathrm{g} / \mathrm{L}$.

A decrease in haematocrit levels in brown trout was already observed after exposure to diclofenac for 7 days. The finding that diclofenac can lead to reduced erythrocyte numbers in peripheral blood is in line with observations in patients on diclofenac therapy and in studies with rats (Elliott et al., 1995; Sanchez et al., 2002). The lower erythrocyte numbers described in humans are thought to be caused by an inhibition of haematopoiesis rather than damage of existing erythrocytes. However, gastric bleeding has also been suggested to be a possible cause for anaemia after treatment with diclofenac (Sanchez et al., 2002).

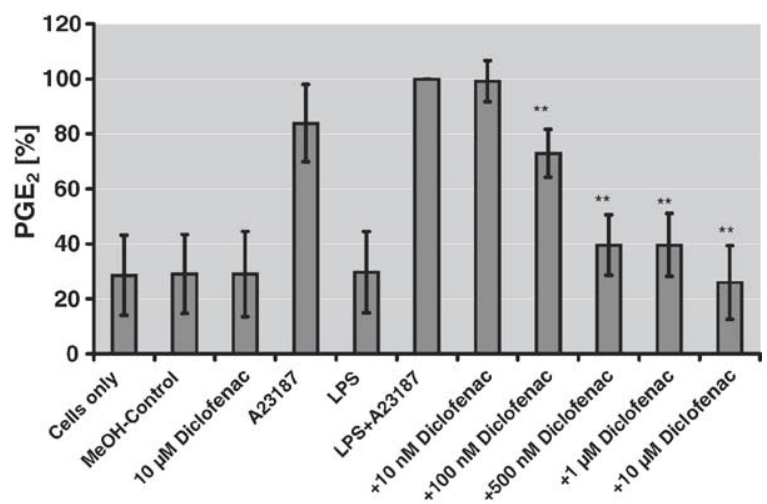

Fig. 5. Prostaglandin $\mathrm{E}_{2}\left(\mathrm{PGE}_{2}\right)$ in cell culture supernatant after stimulation of brown trout ( $S$. trutta f. fario) head kidney macrophages with LPS and the calcium ionophore A23187 and inhibition of $\mathrm{PGE}_{2}$ synthesis by diclofenac; $100 \mathrm{nM}=31.8 \mu \mathrm{g} / \mathrm{L}$ diclofenac. Data was tested with one-way ANOVA with Dunnett's post test against values from LPS + A23187 stimulated cells set at $100 \%$. Shown are mean values with standard deviation; $N=4$, ${ }^{* *} p \leq 0.01$.
Histopathological investigations of organ sections of diclofenac-exposed brown trout revealed adverse effects in trunk kidney, gills and liver. Adverse effects of diclofenac in kidney have previously been described in various species, including rats and vultures, as well as humans (Hickey et al., 2001; Oaks et al., 2004). First indications of adverse effects of diclofenac on fish have been reported by Schwaiger et al. (2004), who described the occurrence of hyaline droplet degeneration in tubular cells and interstitial nephritis in rainbow trout (O. mykiss) kidney after exposure to $5 \mu \mathrm{g} / \mathrm{L}$ for 28 days. Nephrotoxicity of diclofenac is thought to be mainly due to the inhibition of prostaglandin synthesis and subsequent changes in prostaglandin regulated mechanisms, such as vessel tone, vascular permeability and ion regulation (Sanchez et al., 2002). The present study was able to demonstrate that diclofenac can inhibit cyclooxygenase activity and accordingly, synthesis of prostaglandin $E_{2}$ in brown trout head kidney macrophages in vitro, thus demonstrating the same mode of action as reported for mammalian species. In humans, the effects of NSAIDs on prostaglandin synthesis are known to result in hyponatraemia and hyperkalaemia. Hickey et al. (2001) suppose that oxidative damage and subsequent necrosis and possibly apoptotic cell death also play an important role in diclofenac-induced nephrotoxicity. In the present study, immunohistology revealed the existence of an inflammatory response in kidney samples of diclofenac-exposed brown trout characterised by increased granulocyte numbers and increased MHC II expression. This observation supports the idea of an inflammatory process leading to or following kidney damage at lower doses of diclofenac. However, it does 
not clarify the cause of the inflammation, which may be the presence of protein adducts, as previously seen in mammals (Atchison et al., 2000; Hargus et al., 1995), as well as oxidative stress. The detected "inflammatory response" in the 0.5 and $5 \mu \mathrm{g} / \mathrm{L}$ exposed group was not seen in the $50 \mu \mathrm{g} / \mathrm{L}$ group, in which the most prominent histopathological alterations were found. If the increase of MHC II and the infiltration of inflammatory cells is due to morphological alterations, one would expect the strongest effects to occur at $50 \mu \mathrm{g} / \mathrm{L}$ diclofenac. The depressed inflammatory response indicates that in trout exposed to $50 \mu \mathrm{g} / \mathrm{L}$ diclofenac, the immune system's ability to react is also disturbed, which could lead to lower resistance to facultative pathogens.

The histopathological alterations observed in liver of diclofenac-exposed trout, including monocyte infiltration, might also hint at an inflammatory process. However, in liver samples, immunohistology did not demonstrate apparent changes in the prevalence of certain leucocytes populations or MHC II expression, which would support the notion of an inflammatory process. As already stated for the kidney, the cause and concomitant mechanisms underlying the described effects in liver remain unexplained.

Although statistically not significant, the increased incidence of telangiectasis in gill samples of diclofenac-exposed brown trout in the present study is in line with results described by Schwaiger et al. (2004) for rainbow trout $(O$. mykiss) exposed to diclofenac concentrations in the low $\mu \mathrm{g} / \mathrm{L}$ range. Causative factors for telangiectasis are diverse and include parasite infestation, inappropriate sampling techniques and sublethal ammonia intoxication (Bullock et al., 1994; Goodwin, 1999; Herman and Meade, 1985; Powell et al., 2004; Redner and Stickney, 1979). In the present study, the specific cause and mechanism underlying the prevalence of telangiectasis in diclofenac-exposed fish could not be revealed. Diclofenac is a small molecule, with a $\log K_{\text {ow }}$ of 0.7 (sodium-diclofenac) and low lipophilicity. It may therefore easily pass through cell membranes. The high incidence of telangiectasis after diclofenac exposure against a negligible background level in control fish clearly suggests a significant role of diclofenac in the manifestation of telangiectasis in exposed fish. In addition to the observed histopathological effects in gills, immunohistology revealed an increase of granulocyte numbers in primary gill filaments of diclofenac-exposed trout, most prominent in the fish exposed to $0.5 \mu \mathrm{g} / \mathrm{L}$. This infiltration of granulocytes may support the presence of an inflammatory process possibly in response to damage of the vascular endothelium. Adverse effects of diclofenac exposure on gills are possibly related to the role of prostaglandin synthesis in the regulation of ion transport. In mammalians, prostaglandins are known to be principal regulators of blood circulation and ion concentrations in kidney. It is feasible to assume that in fish prostaglandins may also display similar mechanistic roles in the gills, where blood circulation and ion regulation are essential biological mechanisms. Consequently, brown trout exposed chronically to low levels of diclofenac could suffer adverse effects associated with the inhibition of $\mathrm{COX}$ and $\mathrm{PGE}_{2}$ synthesis.

The present study shows that diclofenac can cause serious adverse effects in vertebrate species at much lower concentrations, than suggested by acute or (sub)chronic toxicity testing with invertebrate species (Ferrari et al., 2003, 2004). Calculating predicted environmental concentration/predicted no effect concentration (PEC/PNEC) ratios for these acute and chronic endpoints in invertebrate species using PECs for European rivers, does not show increased risks, as PEC/PNEC ratios remain below 1 (Ferrari et al., 2004). In the present study, a PEC of $0.5 \mu \mathrm{g} / \mathrm{L}$ was calculated according to the latest "Draft Guideline on the Environmental Risk Assessment of Medicinal Products" (EMEA, 2005) based on a maximal therapeutic dose of $100 \mathrm{mg}$ diclofenac/day.

The no observed effect concentration (NOEC) was determined to be $0.5 \mu \mathrm{g} / \mathrm{L}$ for monocyte infiltration/accumulation in livers of brown trout exposed for 21 days, although mild effects were seen in $2 / 6$ trout in the $0.5 \mu \mathrm{g} / \mathrm{L}$ group. The calculation of a PNEC requires the application of assessment factors (AF) of 10 to account for inter-/intraspecies variations and laboratory data to field impact extrapolation. The "Draft Guideline on the Environmental Risk Assessment of Medicinal Products" (EMEA, 2005) states, however, that an AF of 1000 on acute data will not be protective for pharmaceuticals, and that it is considered justified to base the PNEC not on acute, but rather on chronic data. As the data presented here neither represent an acute nor chronic but rather a subchronic exposure situation, an AF of 100 would most likely be the 
most acceptable calculation scenario. A PNEC of $0.005 \mu \mathrm{g} / \mathrm{L}$ was therefore derived as a conservative scenario. This results in a PEC/PNEC ratio of 100 calling for further investigations and a refined risk assessment for this substance. Therefore, if alterations as observed in the present study rather than acute endpoints are considered as an environmental risk, the concentrations regularly found in surface waters have to be regarded as potentially harmful to aquatic vertebrate species. Consequently, pharmaceuticals, e.g. diclofenac can adversely affect exposed non-target species due to their highly specific mode of action and interaction with phylogenetically highly conserved biochemical factors like, e.g. cyclooxygenases. The severity of consequences, which can be expected after disturbances in specific biochemical regulation mechanisms remain uncertain to date. However, it has to be assumed that such subtle alterations as observed in the present study potentially lead to serious adverse effects in fish populations, e.g. through disturbing homeostasis, inducing additional stress and thus possibly lowering resistance against facultative pathogens.

In conclusion, the present study demonstrated that diclofenac residues have the potential to adversely affect various tissues in brown trout at concentrations close to those regularly found in surface waters. The findings of the study prompt the assumption that diclofenac is readily taken up by trout from the surrounding water, with the major uptake path likely being via the gills. In general, the study suggests that diclofenac follows the same mechanisms in fish as found in mammalian species and will thus have the potential to affect similar reactions. In fish, especially alterations in gill physiology have to be considered as particularly problematic, as they will most likely affect oxygen supply and consequently all biochemical reactions depending on oxygen. In spite of the low concentrations found in surface water, chronic exposure to diclofenac residues has to be considered as potentially harmful to fish populations. Subtle, but nevertheless seriously harmful effects of pharmaceutical residues in surface waters, however, cannot be observed in classical acute toxicity testing. Thus, by applying standard methods in testing of environmental toxicity, there is a high possibility of neglecting the potential of such aquatic pollutants to negatively affect aquatic organisms.

\section{Acknowledgements}

The practical help of Martin Zieger, Nadine Richter, Sabine Weber, Helga Noack, Gabriele Czerwinski and Dr. Jens Peter Teifke is gratefully appreciated. Diclofenac antibody and the coating antigen for the diclofenac ELISA were kindly provided by Dr. Dietmar Knopp, Technical University Munich, Germany. The study was financed by Baden-Württemberg Programm Lebensgrundlage Umwelt und Ihre Sicherung (BWPLUS), Karlsruhe, Germany.

\section{References}

Atchison, C.R., West, A.B., Balakumaran, A., Hargus, S.J., Pohl, L.R., Daiker, D.H., Aronson, J.F., Hoffmann, W.E., Shipp, B.K., Treinen-Moslen, M., 2000. Drug enterocyte adducts: possible causal factor for diclofenac enteropathy in rats. Gastroenterology 119, 1537-1547.

Bullock, G., Herman, R., Heinen, J., Noble, A., Weber, A., Hankins, J., 1994. Observations on the occurrence of bacterial gill disease and amoeba gill infestation in rainbow trout cultured in a water recirculation system. J. Aquat. Anim. Health 6, 310-317.

Buser, H.R., Poiger, T., Müller, M.D., 1998. Occurrence and fate of the pharmaceutical drug diclofenac in surface waters: rapid photodegradation in a lake. Environ. Sci. Technol. 32, 3449-3456.

Deng, A., Himmelsbach, M., Zhu, Q.Z., Frey, S., Sengl, M., Buchberger, W., Niessner, R., Knopp, D., 2003. Residue analysis of the pharmaceutical diclofenac in different water types using ELISA and GC-MS. Environ. Sci. Technol. 37, 3422-3429.

Elliott, S.N., McKnight, W., Cirino, G., Wallace, J.L., 1995. A nitric oxide-releasing nonsteroidal anti-inflammatory drug accelerates gastric ulcer healing in rats. Gastroenterology 109, 524-530.

Ellis, A.E., 1990. Lysozyme assays. In: Van Muiswinkel, W.B. (Ed.), Techniques in Fish Immunology. SOS Publications, Fair Haven, pp. 101-103.

EMEA, 2005. Committee for medicinal products for human use (CHMP) - Draft guideline on the environmental risk assessment of medicinal products for human use. European Medicines Agency, London.

Ferrari, B., Mons, R., Vollat, B., Fraysse, B., Paxeus, N., Lo Giudice, R., Pollio, A., Garric, J., 2004. Environmental risk assessment of six human pharmaceuticals: are the current environmental risk assessment procedures sufficient for the protection of the aquatic environment? Environ. Toxicol. Chem. 23, 1344-1354.

Ferrari, B., Paxeus, N., Lo Giudice, R., Pollio, A., Garric, J., 2003. Ecotoxicological impact of pharmaceuticals found in treated wastewaters: study of carbamazepine, clofibric acid, and diclofenac. Ecotoxicol. Environ. Saf. 55, 359-370.

Goodwin, A.E., 1999. Massive Lernaea cyprinacea infestations damaging the gills of channel catfish polycultured with bighead carp. J. Aquat. Anim. Health 11, 406-408. 
Hargus, S.J., Martin, B.M., George, J.W., Pohl, L.R., 1995. Covalent modification of rat liver dipeptidyl peptidase IV (CD26) by the nonsteroidal anti-inflammatory drug diclofenac. Chem. Res. Toxicol. 8, 993-996.

Herman, R.L., Meade, J.W., 1985. Gill lamellar dilations (Telangiectasis) related to sampling techniques. Trans. Am. Fish Soc. 114, 911-913.

Hickey, E.J., Raje, R.R., Reid, V.E., Gross, S.M., Ray, S.D., 2001. Diclofenac induced in vivo nephrotoxicity may involve oxidative stress-mediated massive genomic DNA fragmentation and apoptotic cell death. Free Radic. Biol. Med. 31, 139-152.

Köllner, B., Fischer, U., Rombout, J.H.W.M., Taverne-Thiele, J.J., Hansen, J.D., 2004. Potential involvement of rainbow trout thrombocytes in immune functions: a study using a panel of monoclonal antibodies and RT-PCR. Dev. Comp. Immunol. 28, 1049-1062.

Kuroda, A., Okamoto, N., Fukuda, H., 2000. Characterization of monoclonal antibodies against antigens shared with neutrophils and macrophages in neutrophils in rainbow trout Oncorhynchus mykiss. Fish Pathol. 35, 205-213.

Oaks, J.L., Gilbert, M., Virani, M.Z., Watson, R.T., Meteyer, C.U., Rideout, B.A., Shivaprasad, H.L., Ahmed, S., Chaudhry, M.J., Arshad, M., Mahmood, S., Ali, A., Khan, A.A., 2004. Diclofenac residues as the cause of vulture population decline in Pakistan. Nature 427, 630-633.

Powell, M., Carson, J., van Gelderen, R., 2004. Experimental induction of gill disease in Atlantic salmon Salmo salar smolts with Tenacibaculum maritimum. Dis. Aquat. Org. 61, 179-185.

Redner, B.D., Stickney, R.R., 1979. Acclimation to ammonia by Tilapia aurea. Trans. Am. Fish Soc. 108, 383-388.
Sali, T., 2005. Prostaglandins. In: Vohr, H.-W. (Ed.), Encyclopedic Reference of Immunotoxicology. Springer, Heidelberg, pp. 537-540.

Sanchez, S., Alarcon de la Lastra, C., Ortiz, P., Motilva, V., Martin, M.J., 2002. Gastrointestinal tolerability of metamizol, acetaminophen, and diclofenac in subchronic treatment in rats. Dig. Dis. Sci. 47, 2791-2798.

Schwaiger, J., Ferling, H., Mallow, U., Wintermayr, H., Negele, R.D., 2004. Toxic effects of the non-steroidal anti-inflammatory drug diclofenac. Part I: histopathological alterations and bioaccumulation in rainbow trout. Aquat. Toxicol. 68, 141-150.

Secombes, C.J., 1990. Isolation of salmonid macrophages and analysis of their killing activity. In: Stolen, J.S., Fletcher, T.C., Anderson, D.P., Roberson, B.S., Van Muiswinkel, W.B. (Eds.), Techniques in Fish Immunology. SOS Publications, Fair Haven, pp. 101-103.

Stachowski, A., Hordvik, I., Koppang, E., Köllner, B., 2004. Characterization of anti-salmon MHC class II monoclonal antibodies (abstract, Joint Annual Meeting of the German and Dutch Society for Immunology, Maastricht, October 20-23, 2004). Immunobiology 209, 481.

Ternes, T.A., 1998. Occurence of drugs in German sewage treatment plants and rivers. Water Res. 32, 3245-3260.

Ternes, T.A., Joss, A., Siegrist, H., 2004. Scrutinizing pharmaceuticals and personal care products in wastewater treatment. Environ. Sci. Technol. 38, 392A-399A.

Zou, J., Neumann, N.F., Holland, J.W., Belosevic, M., Cunningham, C., Secombes, C.J., Rowley, A.F., 1999. Fish macrophages express a cyclo-oxygenase- 2 homologue after activation. Biochem. J. 340, 153-159. 